\title{
Ketamine Modulates Zic5 Expression via the Notch Signaling Pathway in Neural Crest Induction
}

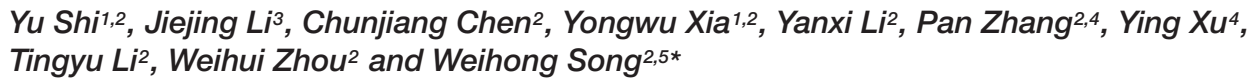

${ }^{1}$ Department of Clinical Laboratory, Children's Hospital of Chongqing Medical University, Chongqing, China, ${ }^{2}$ Chongqing City Key Lab of Translational Medical Research in Cognitive Development and Learning and Memory Disorders and Ministry of Education Key Lab of Child Development and Disorders, Children's Hospital of Chongqing Medical University, Chongqing, China, ${ }^{3}$ Department of Clinical Laboratory, The Affiliated Hospital of KMUST, Medical School, Kunming University of Science and Technology, Kunming, China, ${ }^{4}$ Department of Anesthesiology, Children's Hospital of Chongqing Medical University, Chongqing, China, ${ }^{5}$ Townsend Family Laboratories, Department of Psychiatry, The University of British Columbia, Vancouver, BC, Canada

Ketamine is a potent dissociative anesthetic and the most commonly used illicit drug. Many addicts are women at childbearing age. Although ketamine has been extensively studied as a clinical anesthetic, its effects on embryonic development are poorly understood. Here, we applied the Xenopus model to study the effects of ketamine on development. We found that exposure to ketamine from pre-gastrulation (stage 7) to early neural plate (stage 13.5) resulted in disruption of neural crest (NC) derivatives. Ketamine exposure did not affect mesoderm development as indicated by the normal expression of Chordin, Xbra, Wnt8, and Fgf8. However, ketamine treatment significantly inhibited Zic5 and Slug expression at early neural plate stage. Overexpression of Zic5 rescued ketamine-induced Slug inhibition, suggesting the blockage of NC induction was mediated by Zic5. Furthermore, we found Notch signaling was altered by ketamine. Ketamine inhibited the expression of Notch targeted genes including Hes5.2a, Hes5.2b, and ESR1 and ketamine-treated embryos exhibited Notch-deficient somite phenotypes. A 15 bp core binding element upstream of Zic5 was induced by Notch signaling and caused transcriptional activation. These results demonstrated that Zic5 works as a downstream target gene of Notch signaling in Xenopus NC induction. Our study provides a novel teratogenic mechanism whereby ketamine disrupts NC induction via targeting a Notch-Zic5 signaling pathway.

Keywords: Xenopus, neural crest, ketamine, Notch, Zic5

\section{INTRODUCTION}

Neural crest (NC), the vertebrate-specific pluripotent cell population, derives from the border region between the epidermis and the neural plate. NC gives rise to numerous derivatives including cranial cartilages, neurons and glia of peripheral nervous system, melanocytes, and heart outflow tract (Shi et al., 2014). Abnormal development of NC derivatives results in neurocristopathies, leading to many human congenital disorders such as Hirschsprung disease, Treacher Collins syndrome, Waardenburg-Shah syndrome, DiGeorge syndrome, CHARGE syndrome, neuroblastoma, and melanoma (Bolande, 1997; Takahashi et al., 2013; Monsoro-Burq, 2015). 
The development of NC undergoes induction, specification, migration, and differentiation, which is tightly regulated by a well-orchestrated gene regulatory network (GRN). After germ layer separation, a set of transcription factors including Pax3, Zic1, Zic5, Msx1, Hairy2, Ap2 $\alpha$, and c-Myc are expressed at the border region between the neural plate and the epidermis. Such expression is induced by morphogens like Wnt, BMP, FGF, Notch and retinoic acid in a gradient sensitive manner. These border determination transcription factors further trigger the expression of a group of genes including Slug, FoxD3, Snail, Sox9, and Twist in the emerging NC cells, thereby accomplishing NC induction (Steventon et al., 2005; Milet and Monsoro-Burq, 2012; Shyamala et al., 2015). After induction, the NC cells undergo epithelial to mesenchymal transition (EMT) and migrate to their destination in a contact inhibition of locomotion manner (Theveneau and Mayor, 2012). Terminal differentiation of NC cells is extensively cross-regulated by different networks.

The Notch signaling pathway plays vital roles in early embryonic development (Artavanis-Tsakonas et al., 1995, 1999). Following ligand binding, the Notch receptor is cleaved continuously by an ADAM (Brou et al., 2000; Mumm et al., 2000; Dyczynska et al., 2007; Bozkulak and Weinmaster, 2009) and $\gamma$-secretase complex (De Strooper et al., 1999; Song et al., 1999; Zhang et al., 2000) and releases the active N-terminal intracellular domain (NICD). The NICD then translocates to nucleus and interacts with CSL family DNA binding proteins to activate the transcription of downstream target genes (Schroeter et al., 1998; Struhl and Adachi, 1998). Activation of the Notch signaling pathway by binding to adjacent cells facilitates boundary determination. During NC induction, Notch and its ligands are expressed in the prospective anterior NC territory, where Notch coordinates with the BMP signal to determine the NC border region. In somitogenesis, the expressed protein amount of the NICD in nucleus forms a cyclical clock manner through degradation and thereby establish somite boundary formation (Dale et al., 2003).

Notch signaling pathway has been shown to play a role in NC development in different animal models. Disturbance of Notch signaling in mice leads to craniofacial structure abnormity, cardiac outflow deficiency, and decreased enteric neurons (Okamura and Saga, 2008; Mead and Yutzey, 2012). Notch signals refine the neural plate border region through negative regulation of PRDM1 $\alpha$ in zebrafish (Hernandez-Lagunas et al., 2011). Studies using chick and Xenopus models demonstrate a similar BMP-regulating mechanism of Notch pathways in NC development (Endo et al., 2002). Hairy family genes required for NC induction are down-regulated by BMP-Smad signaling and positively regulated by the Notch/Delta-Su(h) pathway (VegaLopez et al., 2015). Another report suggests a role for Tsk in balancing Notch and BMP pathways via directly binding to BMP and the extracellular domain of Delta1 during neural plate border determination in Xenopus (Kuriyama et al., 2006).

Ketamine has been commonly used as anesthetic, analgesic, or sedative, and has recently been shown to be a promising acute anti-depressant (Ionescu et al., 2015; Kirby, 2015; Reardon, 2015). As a dissociative anesthetic, ketamine users can develop cravings for the drug and become addicted. Ketamine is now one of the most popular and most abused recreational illicit drugs in the world. A large number of the drug users are women at childbearing ages. The impact of illicit ketamine use on embryonic development during pregnancy could be detrimental. Previous studies using zebrafish, Xenopus and rat models showed its disruptive effects on motor-neuron development (Kanungo et al., 2013), primary germ cell layers specification (Akeju et al., 2014), cardiac morphogenesis (Guo et al., 2016), neural genesis and survival (Dong and Anand, 2013; Dong et al., 2014). More recently, a report suggested craniofacial and trunk phenotypes upon embryonic ketamine exposure in Zebrafish (Felix et al., 2017). Furthermore, ketamine has been shown to act as teratogen in a NMDA-independent ways (Felix et al., 2014). Although ketamine's roles as NMDA antagonist have been extensively studied, the effect on early embryonic development and its underlying mechanisms remain elusive.

In this study, we report that ketamine exposure affected NC development at a very early stage, equivalent to the first month of human pregnancy. Ketamine down-regulates Zic5 expression in the presumptive neural plate border region and thereby disrupting NC induction. Our data indicate that ketamine disturbs Notch signaling, and that Zic5 works downstream of Notch during Xenopus NC developmental stages. Our data suggest a completely new teratogenic mechanism whereby ketamine disrupts NC induction via targeting a NOTCH-Zic5 signaling pathway.

\section{MATERIALS AND METHODS}

\section{Microinjection and in Situ Hybridization}

This study was carried out in accordance with the recommendations of the animal study guideline of the Animal Experimentation Ethical Committee of Chongqing Medical University. The protocol was approved by the Animal Experimentation Ethical Committee of Chongqing Medical University in Chongqing, China. Embryo in vitro fertilization, culture, whole mount in situ hybridization, mRNA preparation and microinjection were carried out as previously described (Shi et al., 2009, 2014). The probes for whole-mount in situ hybridization including Chordin, Xbra, Wnt8, Fgf8, Msx1,Pax3, Zic1, Zic5, Slug, Six1, MyoD were applied as described (Smith et al., 1991; Sasai et al., 1994; Nakata et al., 2000; Li et al., 2006; Guemar et al., 2007; Zhang et al., 2014). For enteric neuron labeling, intestines were first manually dissected out from stage 40 embryos which were freshly fixed with $4 \%$ paraformaldehyde. Then the enteric neurons were stained through in situ hybridization with $\mathrm{N}$-tubulin probe (Oschwald et al., 1991).

\section{Cranial Cartilage Staining, Immunohistochemistry, and RT-PCR}

The cranial cartilage staining was performed as previously described (Shi et al., 2014). For immunohistochemistry, embryos were collected at stage 40 and fixed with paraformaldehyde. The frozen samples were sectioned in $10 \mu \mathrm{m}$ thickness, and stained with $\beta$-tubulin III (Sigma T8660). Total RNA samples 
were extracted with Trizol kit (Tiangen) and reversely transcribed with Fermentas RevertAid First Strand cDNA synthesis kit (Thermoscientific 1622). The RT-PCR primers for Fgf8, Wnt8, Dlx3, Dlx5, AP2 $\alpha$, Pax3, Msx1, Zic1, Zic5, Slug, Hes5.2a, Hes5.2b, ESR1, and Histone4 (H4) were listed in Table 1.

\section{Western Blot Analysis}

T-Leukemia cell lines Jurkat were cultured with $2 \mathrm{mM}$ ketamine for $10 \mathrm{~h}$ and collected for WB. The Antibodies used were Notch-1 antibody (Cell Signaling 3608, 1:1000), GAPDH (Enogene E12052-4, 1:5000). For Notch ubiquitin assay, 5 MM MG132 (Sigma) was added with or without ketamine into the media, Jurkat cells were then lysed and precipitated with Notch-1 antibody (1:50) and then bound with protein A/G (Santa Cruz sc-2003). Antiubiquitin (Santa Cruz sc-8017) antibody were applied to detect ubiquitinated proteins.

\section{Luciferase Reporter Assays}

Different fragments (100 bp-4 kb) upstream of Xenopus tropicalis Zic5 gene were cloned and linked with XhoI and MluI restrictive site into pGL3-basic to generate the firefly reporter constructs. The primers for different lengths of $X$. tropicalis Zic5 upstream regulatory sequences are: reverse primer XhoI: $5^{\prime}$-ccctcgagtgtctgcctcccaactct; -4042 forward: 5'-cgacgcgttgaga tggcgagtaggct; -1950 forward MluI: $5^{\prime}$-cgacgcgttccttattagtgtatata; -532 forward: $5^{\prime}$-cgacgcgttgcacaactataggtctatt; -286 forward: 5'-cgacgcgtctccaaactttctacaagtg; -200 forward: 5'-cgacgcgtcagcc agccaatcagaaaag; $-200 \mathrm{~m}$ forward: $5^{\prime}$-cgacgcgtttctaattaaggattg aaaagcgggcctcc; -186 forward: 5'-cgacgcgtgaaaagcgggcctcctgcc. To mutant canonical CSL binding site, mutant kit (Takara R401) as well as template construct pXzic5 -4042/-29 was applied according to the manufacture with primers: for 3950 site forward $5^{\prime}$-atgtattgcttcgaccttggcattttgg, reverse $5^{\prime}$-gtttctacattttccaaagttgtgcaaag; for 65 site forward $5^{\prime}$-ggac agacctacggaaggaataagc, reverse $5^{\prime}$-ctccagcgattggcagaaagcg.

To measure the reporter activity in embryos, $12.5 \mathrm{pg}$ constructed firefly plasmid, $2.5 \mathrm{pg}$ renilla construct and $500 \mathrm{pg}$ NICD mRNA or 500 pg LacZ mRNA (for control) were co-injected into both side of the dorsal blastomeres at the 4-cell stage. The embryos were then harvested at the neural plate stage (stage 15), divided into three groups (> 10 embryos each group), lysed and analyzed using Dual-Luciferase Reporter Assay System (Promega).

\section{Electrophoretic Mobility Shift Assay (EMSA)}

SHSY-5Y cell line was transfected with pcDNA4-NICD or pcDNA empty vector. Nuclear protein was extracted. EMSA was performed as described previously with minor adjustment (Wang et al., 2011). Briefly, $20 \mu \mathrm{g}$ protein was incubated with IRDye700labeled binding oligo (5'-gcctgacagccagccaatca) or mutant oligo $\left(5^{\prime}\right.$-gactaacaaccatccaaaca) respectively, and the gels were analyzed

\begin{tabular}{|c|c|c|c|c|c|}
\hline Gene & Primers (forward and reverse) & Cycles & Annealing temperatures $\left({ }^{\circ} \mathrm{C}\right)$ & Extension time (s) & Reference \\
\hline Fgf8 & $\begin{array}{l}\text { 5'-TGCGGAGACTGGTTACTACATCTG-3' } \\
\text { 5'-TTCTGTGGTGTGGTGTCCCTTGG-3' }\end{array}$ & 28 & 55 & 30 & Monsoro-Burq et al., 2003 \\
\hline Wnt8 & $\begin{array}{l}\text { 5'-GACAAGATGCCAGAGCCCTAA-3' } \\
\text { 5'-TAAGTTCAGACCCGGCCACA-3' }\end{array}$ & 28 & 55 & 30 & Zhang et al., 2014 \\
\hline Dlx3 & $\begin{array}{l}\text { 5'-TCGGCCGTITGTCCATTACA-3' } \\
\text { 5'-GGTTTCGGGCTCTTCCTTCA-3' }\end{array}$ & 26 & 55 & 30 & Zhang et al., 2014 \\
\hline Dlx5 & $\begin{array}{l}\text { 5'-ATTCTCCCCAGTCTCCAGTG-3' } \\
\text { 5'-GATAGTGTCCCCAGTTGCGC-3' }\end{array}$ & 26 & 55 & 30 & This work \\
\hline $\operatorname{AP} 2 \alpha$ & $\begin{array}{l}\text { 5'-GGACCTGCCTITACATCCATACC-3' } \\
\text { 5'-CCTCCGTIITAGATITGCCC-3' }\end{array}$ & 28 & 55 & 30 & de Croze et al., 2011 \\
\hline Pax3 & $\begin{array}{l}\text { 5'-TCTCACTCTCTCTITACAGGGGGAC-3' } \\
\text { 5'-TCTTGTGCCTTATGTGGTTGGG-3' }\end{array}$ & 29 & 55 & 30 & Monsoro-Burq et al., 2005 \\
\hline Msx1 & $\begin{array}{l}\text { 5'-ACTGGTGTGAAGCCGTCCCT-3' } \\
\text { 5'-TTCTCTCGGGACTCTCAGGC-3'3 }\end{array}$ & 29 & 55 & 30 & Su et al., 1991 \\
\hline Zic1 & $\begin{array}{l}\text { 5'-ATGAAGGTCCACGACGAAGCATC-3' } \\
\text { 5'-CGTGCTGTGATTGGACGTGT-3'3 }\end{array}$ & 30 & 55 & 30 & Mizuseki et al., 1998 \\
\hline Zic5 & $\begin{array}{l}\text { 5'-AGAGAGGACTATACGCTAAC-3' } \\
\text { 5'-GGTACATGAGAGCAGAGAAC-3' }\end{array}$ & 27 & 55 & 30 & Nakata et al., 2000 \\
\hline Slug & $\begin{array}{l}\text { 5'-TCCCGCCACTGAAAATGCCACGATC-3' } \\
\text { 5' -CCGTCCTAAAGATGAAGGGTATTCCTG-3' }\end{array}$ & 28 & 55 & 30 & Mizuseki et al., 1998 \\
\hline Hes5.2a & $\begin{array}{l}\text { 5'-GGCATTGGTAGAAGCAGTC-3' } \\
\text { 5'-CCAGTTAACCTTGGGTGTC-3' }\end{array}$ & 28 & 55 & 30 & This work \\
\hline Hes5.2b & $\begin{array}{l}\text { 5'-AGCAGAAGCCAAGCTAATC-3' } \\
\text { 5'-AGGACCATAACCGAACAAG-3' }\end{array}$ & 28 & 55 & 30 & This work \\
\hline ESR1 & $\begin{array}{l}\text { 5'-ACAAGCAGGAACCCAATGTCA-3' } \\
\text { 5'-GCCAGAGCTGATTGTITGGAG-3' }\end{array}$ & 28 & 55 & 30 & Kinoshita et al., 2011 \\
\hline $\mathrm{H} 4$ & $\begin{array}{l}\text { 5'-CGGGATAACATTCAGGGTATCACT-3' } \\
\text { 5'-ATCCATGGCGGTAACTGTCTTCCT-3' }\end{array}$ & 24 & 55 & 30 & Kinoshita et al., 2011 \\
\hline
\end{tabular}


using an Odyssey system (LI-COR Biosciences). Unlabeled wildtype and mutant oligonucleotides at X100 molar excess were applied for the competition assay.

\section{RESULTS}

\section{Embryonic Ketamine Exposure Results in Neurocristopathies}

Previous data indicates that $2 \mathrm{mM}$ ketamine applied in culture yields approximately $0.4 \%$ accumulation, i.e., $8 \mu \mathrm{M}$ inside embryo (Cuevas et al., 2013), which is comparable to the anesthetic concentration in human plasma (Dong et al., 2014). $2 \mathrm{mM}$ or similar culture concentration was commonly chosen to evaluate the embryonic ketamine exposure in most studies (Kanungo et al., 2013; Felix et al., 2014; Lantz-McPeak et al., 2015; Robinson et al., 2015). To examine ketamine's effects on early embryonic development, we exposed Xenopus embryos to $2 \mathrm{mM}$ ketamine-MBS culture media from pre-gastrulation (stage 7) to early neural plate (stage 13.5), and then cultured in MBS media until harvest time. Upon ketamine incubation, pigment cells in trunk diminished and eyes exhibited developmental abnormities (Figure 1A). Ocular pericytes located in retina ganglionic cell layer (GCL) and inner nuclear layer (INL) are derived from the NC (Trost et al., 2013). Further analysis showed disorganization of GCL, INL, and outer nuclear layer (ONL) (Figure 1B DAPI stain, white arrow) and loss of $\beta$-tubulin III expression in cell layer boundary (Figure 1B, white arrowhead) and lens (Figure 1B, asterisk) expression, indicating abnormal differentiation of lens and retina. At the tailbud stage, ketamine caused enlargement of intestinal system combining loss of enteric nervous cells (Figure 1C, black arrowhead), a mega-colon like (Hirschsrpung disease) phenotype (Figure 1C) and marked reduction or even complete loss of all the cranial cartilage elements including Meckel's (Mk), ceratohyal (ch), basihyal (bh), and branchial (ba) cartilages as demonstrated by alcian blue staining (Figure 1D). These data clearly indicate that ketamine impairs NC development, causing neurocristopathies.

\section{Ketamine Blocks NC Induction Independent of Mesoderm Genesis}

Induction is the first event in NC genesis. To investigate the effect of ketamine on NC induction, we examined the expression pattern of the NC specification gene Slug. The criteria for judging the expression pattern are based on two aspects, expression
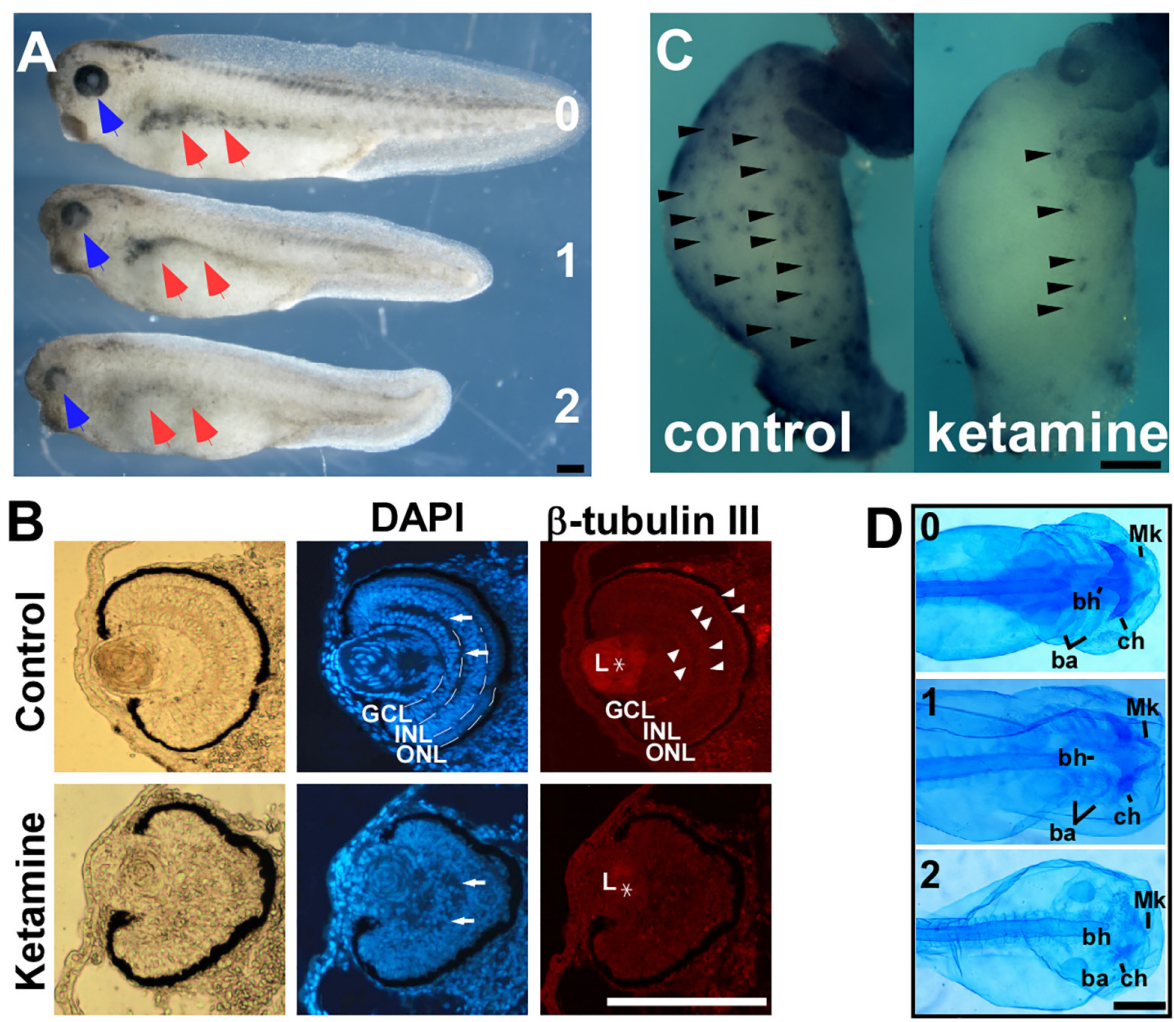

FIGURE 1 | Ketamine exposure results in neurocristopathies. Upon ketamine exposure from stage 7 to stage 13.5. (A) Embryos exhibit shortened axis, faded trunk pigment (red arrowhead), and deficient eyes (blue arrowhead) at tailbud stage and severity of phenotypes are in a dose-dependent manner. (B) Sections of eyes in ketamine-treated embryos revealed a more rounding shape pigment, disorganized arrangement of cells (DAPI staining), reduced expression of $\beta$-tubulin III compared with the control group. Ketamine exposure also causes embryos to develop a mega-colon like phenotype (C), and cranial cartilage atrophy (D). GCL, ganglionic cell layer; INL, inner nuclear layer; ONL, outer nuclear layer; L, lens; Mk, Meckel's cartilage; ch, ceratohyal cartilage; bh, basihyal cartilage; ba, branchial cartilage. Numbers in (A,D) indicate ketamine exposure concentration (mM) to embryos. Scale bar: (A-C) $100 \mu \mathrm{m}$, (D) $1 \mathrm{~mm}$. 
area and intensity. Compared to control, decreased expression area or signal intensity was determined as 'reduced expression level.' At the early neural plate stage (stage 14), when the NC has been induced, control embryos express a normal Slug expression pattern (in 32/32 embryos) (Figure 2A). However, ketamine at a $0.36 \mathrm{mM}$ culture concentration showed reduced Slug expression (36/37). The inhibition of Slug expression increases in a dose dependent manner. At a $2 \mathrm{mM}$ ketamine concentration, Slug expression was severely reduced (41/41) (Figure 2A). Morphogens from the mesoderm are critical for inducing the NC (Klymkowsky et al., 2010). Thus, we examined mesoderm development by in situ hybridization assay with mesoderm markers on the ketamine-incubated and control embryos prior to NC induction (stage 11.5) (Figure 2B). There

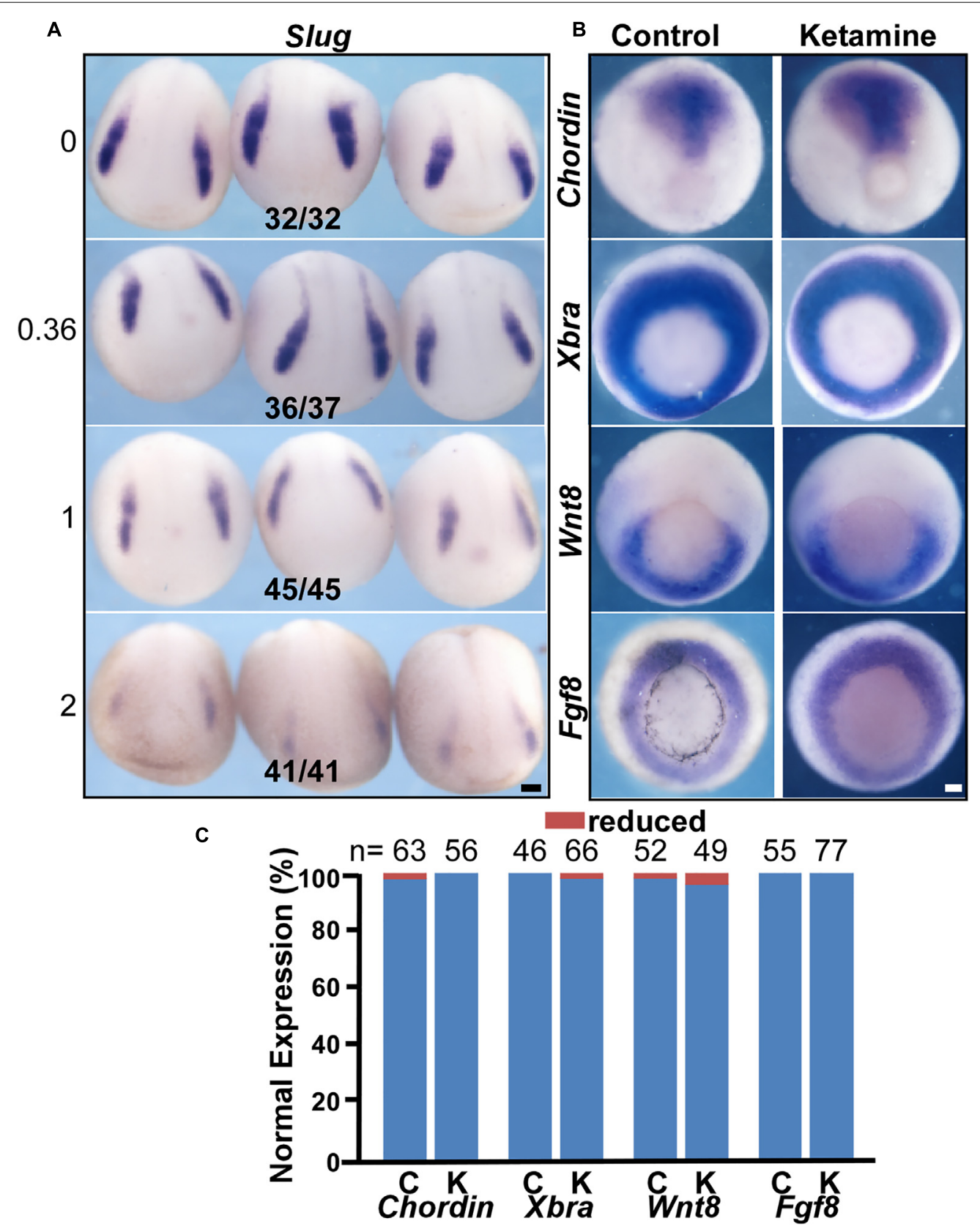

FIGURE 2 | Ketamine blocks NC induction independent of mesoderm genesis. (A) The expression of the NC marker gene Slug was inhibited by ketamine in a dose-dependent manner. The numbers of embryos showing similar changes in gene expression and total embryos in each concentration group are indicated. (B) Early mesoderm development is not affected upon ketamine exposure. There were no significant differences in the expression pattern of mesoderm marker genes chordin, Xbra, Wnt8, and Fgf8 between control and ketamine-treated group prior to NC induction. (C) Quantitative analysis of gene expression patterns between control and ketamine group. Scale bar: $100 \mu \mathrm{m}$. 
was no significant difference between ketamine and control groups in the expression pattern of four mesoderm maker genes including Chordin (100\% normal expression for ketamine, $n=56$; and $98.41 \%$ normal expression for control, $n=63$ ), Xbra (98.48\% normal expression for ketamine, $n=66$; and $100 \%$ normal expression for control, $n=46)$, Wnt8 (95.92\% normal expression for ketamine $n=49$; and $98.08 \%$ normal expression for control, $n=52)$, and $F g f 8$ (100\% normal expression for ketamine, $n=77$; and $100 \%$ normal expression for control, $n=55$ ) (Figure 2C). These results suggest that ketamine does not affect mesoderm at the beginning of NC induction. These data indicate that ketamine blocks NC induction independent of mesoderm genesis.

\section{Ketamine Disrupts NC Induction by Inhibiting the Expression of Zic5}

Neural crest induction requires high Wnt and intermediate BMP signaling input (Steventon et al., 2009). At the onset of gastrulation, animal cap, a pluripotent cell group located in at the animal pole of Xenopus embryos, can develop into almost any cell type given the proper signaling stimulation in vitro. In Xenopus animal caps, co-injection of Wnt8 and BMP4 truncated receptor (tBR) mimics endogenous $\mathrm{NC}$ stimulation and results in the expression of NC genes (Zhang et al., 2014). To determine the targeting molecules mediating ketamine's effect on NC induction, we first examined gene expression in the wnt8-tBR co-injected animal cap system. The default of animal cap cells is an epidermis fate, characterized by a high BMP signaling niche (Linker et al., 2009; Montagner et al., 2016). BMP target genes Msx1 (Tribulo et al., 2003), Dlx3, Dlx5 (Luo et al., 2001; McLarren et al., 2003) and AP2 $\alpha$ (Luo et al., 2002, 2003) are involved in neural plate border determination and are normally expressed in control animal caps. Co-injection of $500 \mathrm{pg}$ Wnt8 mRNA and $500 \mathrm{pg}$ $t B R$ mRNA successfully triggers animal cap cells to express the secreted genes Fgf8, Wnt8, and neural border genes including Zic1, Pax3, Zic5 as well as NC specific genes Slug (Figure 3A). In the presence of ketamine, Wnt8-tBR induced animal caps markedly reduces the expression of Zic5 and Slug (Figure 3A). Zic5 is expressed in the NC area and plays an indispensable role in the induction process (Nakata et al., 2000). Since embryos undergo NC induction in the late gastrula (approximate at stage 12.5), we examined the NC markers at this critical time with a 1-2 $\mathrm{mM}$ ketamine exposure or $0.8 \mathrm{nmol}$ direct injection. At stage 12 the pre-induction state, neither control nor ketaminetreated embryos expressed Slug. At stage 13, all of the NC regulatory network genes were expressed in control embryos, whereas Zic5 and Slug transcripts were reduced in embryos cultured in the ketamine-containing media or directly injected with ketamine. However, the Zic5 and Slug expression levels from whole embryos returned to normal at the beginning of $\mathrm{NC}$ migration (stage 16). The recovery NC gene expression may be due to the feedback of complicated GRNs (Figure 3B). Consistent with RT-PCR data from animal caps and whole embryos, in situ hybridization results showed that ketamine treatment did not affect most NC induction-related genes including Fgf8 (97.96\% normal expression, $n=49)$, Wnt8 (100\% normal expression, $n=77)$, Msx1 (100\% normal expression, $n=66)$, Pax3 $(97.56 \%$ normal expression, $n=41$ ), and Zic1 (96.15\% normal expression, $n=52$ ) (Figures 3C,F). However, the expression of Zic5 and the induction marker gene Slug were markedly inhibited by ketamine, with 97\% $(n=70$,$) and 100 \%(n=43)$ of embryos having inhibited expression respectively (Figures 3D,F). Finally, exogenous injection of Zic5 mRNA at two-cell stage significantly rescued the ketamine-induced Slug inhibition (63.64\% of normal expression, $n=44$ ) (Figures 3E,F). Our data suggest that ketamine disrupts NC induction by inhibiting Zic5 expression.

\section{Targeting Zic5 by Notch Signaling in NC Induction}

To investigate the upstream signaling pathways mediating ketamine-induced Zic5 inhibition during NC induction, we screened the most common NC induction morphogens including Wnt, Fgf, and Notch. Previous work showed that prospective paraxial mesoderm or Fgf8 induces Zic5 expression (MonsoroBurq et al., 2003). Our results show that $F g f 8$ and its downstream NC inducing gene Msxl (Monsoro-Burq et al., 2005) were normally expressed and not affected by ketamine treatment (Figure 3). However, ketamine exposure markedly reduced the expression of Notch target genes Hes5.2a, Hes5.2b, and ESR1 (Figure 4A). Somite labeling with $M y o D$ and Sixl transcripts showed slightly reduced signal (Figure $4 \mathrm{~B}$ ) and a shortened embryonic body axis (Figure 1A) that mirrors phenotypes seen in Notch-deficient embryos (Jen et al., 1997). To analyze ketamine's effect on Notch signaling, the human T-cell leukemia line Jurkat was used. $2 \mathrm{mM}$ Ketamine exposure for $10 \mathrm{~h}$ increased the amount of ubiquitinated Notch (Figure 4C) and promoted Notch protein degradation (Figure 4D). To ask whether Zic5 functions as a downstream target gene of Notch signaling, we assayed Zic5's response to high and low Notch environment during NC induction in Xenopus embryos. Blocking Notch pathway with microinjection of Delta-stu mRNA (Revinski et al., 2010) at the 4-cell stage markedly inhibited Zic5 expression (Figure 4E). Activation of Notch signaling by injection of NICD (Fryer et al., 2002) induced Zic5 ectopic expression in whole neural plate and $\mathrm{NC}$ area (Figure $4 \mathrm{E}$ ).

\section{Identification of a 15 bp cis-Acting Notch-Response Element in the Zic5 Upstream Regulatory Region}

To investigate the molecular mechanism underlying Notch's effect on Zic5, we first examined whether the Zic5 gene contains Notch response element (NRE) in its upstream regulatory region. A 4013 bp containing sequence, between -4042 and -29 bp upstream of the translation start codon (designated as +1 ), for the X. tropicalis Zic5 gene was cloned into pGL3-basic to generate a firefly luciferase gene reporter construct pXzic5$4042 /-29$. Sanger sequencing confirmed the insertion of -4042 to -29 as identical to $117367902-117371914$ of chromosome 2 (Xenbase/X. tropicalis Gbrowse 9.0). This $4 \mathrm{~kb}$ sequence contains two putative canonical Notch signaling CSL binding elements (GTGGGAA) in -65 to -58 (chromosome 2, 1173187911731885 ) and in -3950 to -3944 (chromosome2, 1173197111731977) upstream of Zic5. To check the promoter activity 

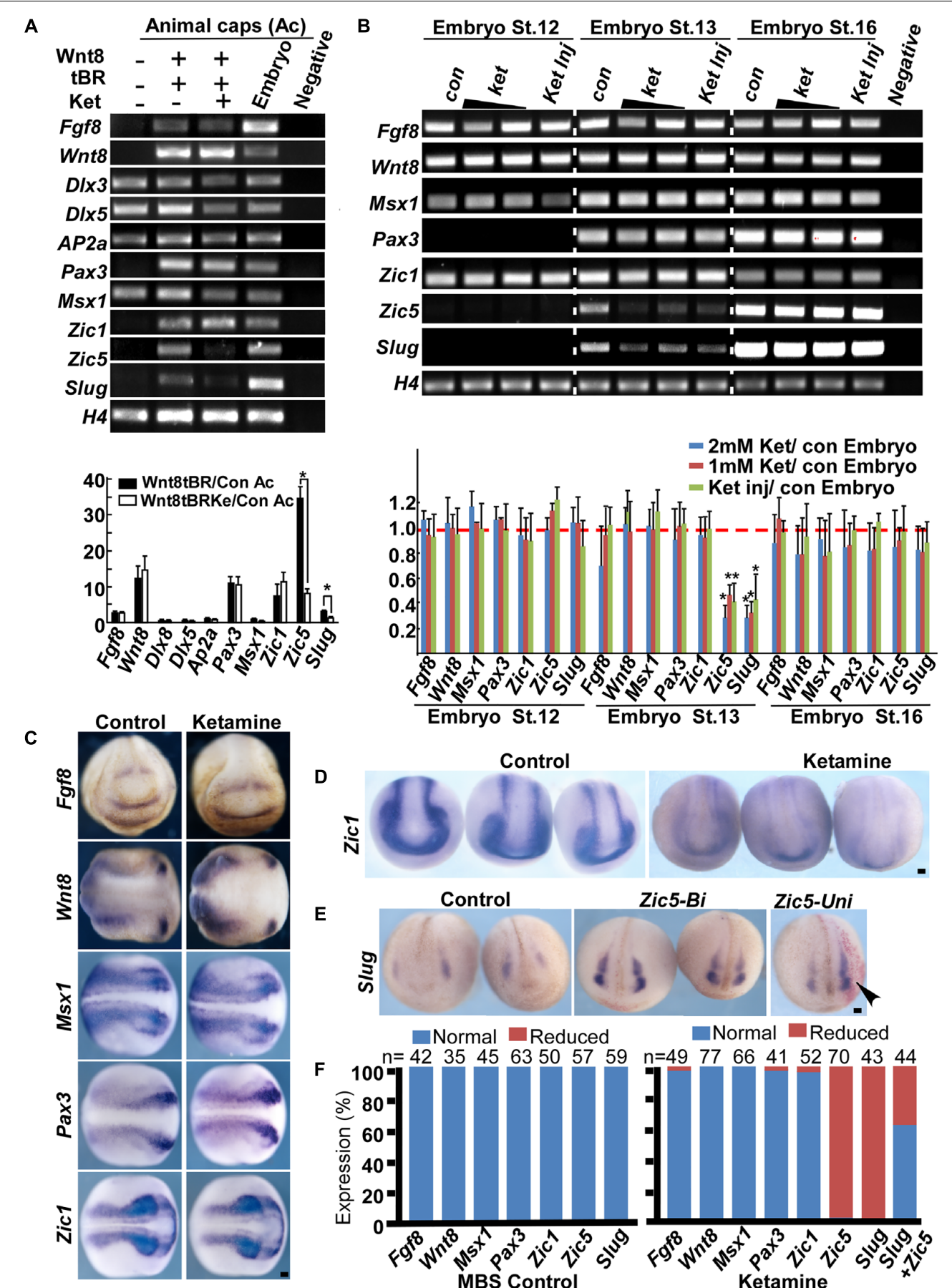

D
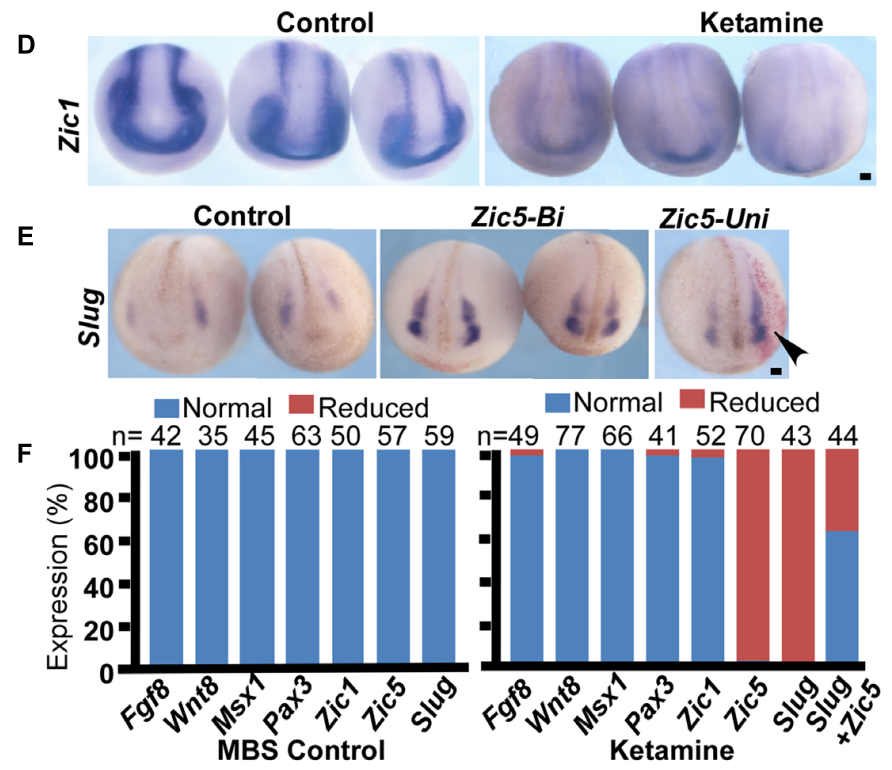

FIGURE 3 | Ketamine targets Zic5 in NC induction. (A) In animal caps, Wnt8 (500 pg) and tBR (500 pg) induce expression of NC markers (lanes 1, 2). Upon ketamine exposure, the expression of Zic5 and S/ug were inhibited (lanes 2, 3). The induced expression of Zic5 and Slug were reduced by ketamine treatment in animal cap. Gene expressions were normalized with H4. Data are shown as folds over the control animal caps. 15 animal caps were isolated for each group for single time experiments. The number represents Mean $\pm \mathrm{SEM}, N=3,{ }^{*} P<0.05$ by ANOVA. (B) In whole embryos, either ketamine exposure or injection ( $0.8 \mathrm{nmol} / \mathrm{embryo}$ ) blocked Zic5 and S/ug expression at stage 13 (when the NC is being induced) but not stage16 (at the onset of NC migration). Ketamine treatment did not affect most of the border genes from stage 12 to stage 16, but significantly blocked Zic5 and NC gene Slug at stage 13. For a single time experiment, 10 embryos were collected for each group for RT-PCR. Data are shown as folds over the control embryos. The number represents Mean $\pm \mathrm{SEM}$. $N=3,{ }^{*} P<0.05$ by ANOVA. (C) In situ hybridization suggests genes involved in NC induction, including Fgf8, Wnt8, Msx1, Pax3, and Zic1 were not affected by ketamine exposure. (D) Ketamine inhibited Zic5 expression comparing with MBS cultured control group. (E) The inhibition of Slug expression by ketamine was rescued by injection of Zic5 mRNA (500 pg) in both sides or unilaterally. Arrowhead indicate the unilaterally injected side. (F) Quantitative analysis of in situ hybridization results, left: MBS control group, right: ketamine exposure group. ${ }^{*} P<0.05$ with $t$-test. Con, control; Ket, ketamine; Ket Inj, ketamine injection; St., stage; Zic5-Bi, zic5 bilateral injection; Zic5-Uni, zic5 unilateral injection. Scale bar: $100 \mu \mathrm{m}$. 

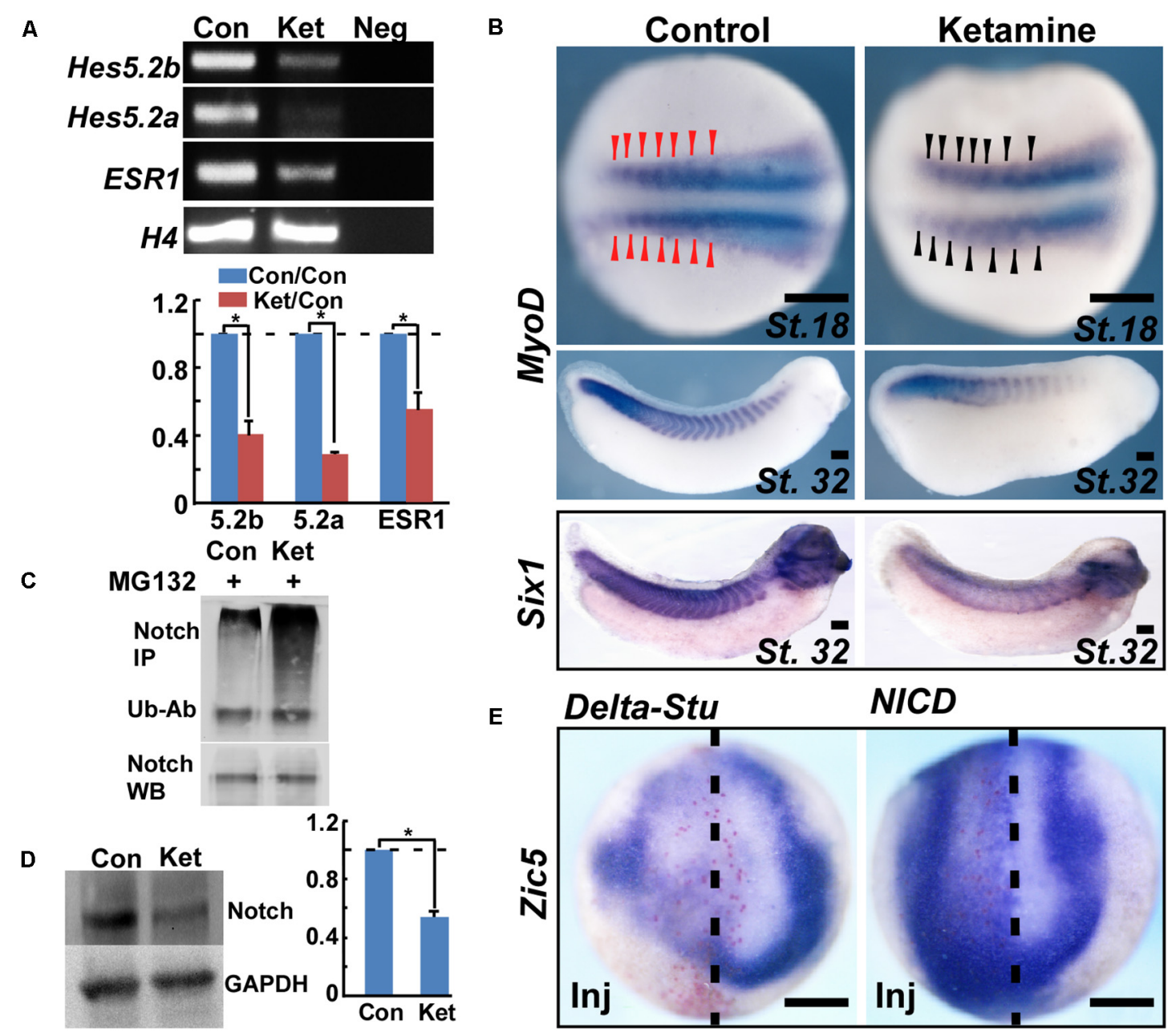

FIGURE 4 | Ketamine inhibits Zic5 through the Notch signaling pathway. (A) During NC induction, ketamine exposure down-regulated expression of Notch targeted genes including Hes5.2a, Hes5.2b, and ESR1. The number represents Mean $\pm \mathrm{SEM}, N=3,{ }^{*} P<0.05$ by Student's $t$-test. (B) In the late neurula, MyoD transcription in early somite primordium became a little bit thin and slightly reduced the signal upon ketamine exposure. At tailbud stage, ketamine led to fewer somites and a shortened body axis. The somites are labeled with in situ hybridization of MyoD, and Six1. (C) Ketamine exposure increased the amount of ubiquitinated Notch protein in Jurkat cells. Upper part: ubiquitinated Notch proteins were immuno-precipitated (IP) with Notch-1 antibody, followed by anti-ubiquitin antibody (Ub-Ab) western blot staining. Lower part: Notch-1 loading control. (D) In Jurkat cells, ketamine exposure for $10 \mathrm{~h}$ reduced Notch protein level. The number represents Mean SEM, $N=3, P<0.05$ by Student's $t$-test. (E) During NC induction, inhibiting Notch signaling by microinjection of 1 ng Delta-stu mRNA at 4 -cell stage blocked Zic5 expression. Activation of Notch signaling by microinjection of 800 pg NICD mRNA into one dorsal cell at 4-cell stage induced ectopic Zic5 expression. Scale bar: $100 \mu \mathrm{m}$.

and the involvement of these two CSL cis-acting binding elements, pXzic5 (-65M)-4042/-29 carrying the -65 binding site mutation to CCTACGG, pXzic5 (-3950M)-4042/-29 carrying the -3950 binding site mutation to CCTACGG, and pXzic5 (DM) -4042/-29 carrying both binding site mutations to CCTACGG were generated for reporter assays (Figure 5A). NICD mRNA or LacZ mRNA (mock stimuli), and pXZIC54042/-29 or relative $4 \mathrm{~kb}$ insertion containing CSL mutant firefly constructs were co-injected into both dorsal blastomeres (that target the neural plate and NC area) at 4-cell stage. A Renilla luciferase construct was also co-injected into embryos as the normalization control. Upon NICD stimulation, pXzic5-4042/29 (1.59 $\pm 0.23 \mathrm{RLU})$, pXzic5 (DM)-4042/-29 (1.51 \pm 0.06 RLU), pXzic5 (-3950M)-42/-29 (1.49 \pm 0.07 RLU) and pXzic5
(-65M)-42/-29 (1.37 $\pm 0.13 \mathrm{RLU})$ reveal significant high luciferase expression level $(P<0.05)$ compared with negative control (LacZ) stimulated pXzic5-4042/-29 (0.05 \pm 0.01 RLU) group in Xenopus Embryos. Transcriptional activity exhibited no statistical difference among the $4 \mathrm{~kb}$ wild-type and the putative CSL-binding site mutant constructs (Figure 5A). Our data suggest that there is functional NRE within region 4042 to -29 , however, the two putative canonical CSL binding sites did not account for Notch-activated Zic5 transcriptional activation.

To identify the NRE, a series of deletion plasmids, covering various regions of this $4 \mathrm{~kb}$ fragment were cloned. Figure 5B showed that NICD significantly activated the luciferase report plasmids containing -4042 bp (2.49 \pm 0.62 RLU), -1950 bp 
A

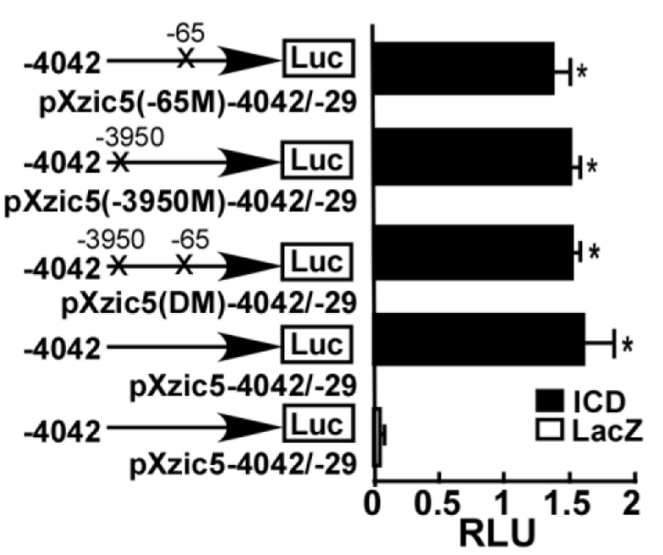

B

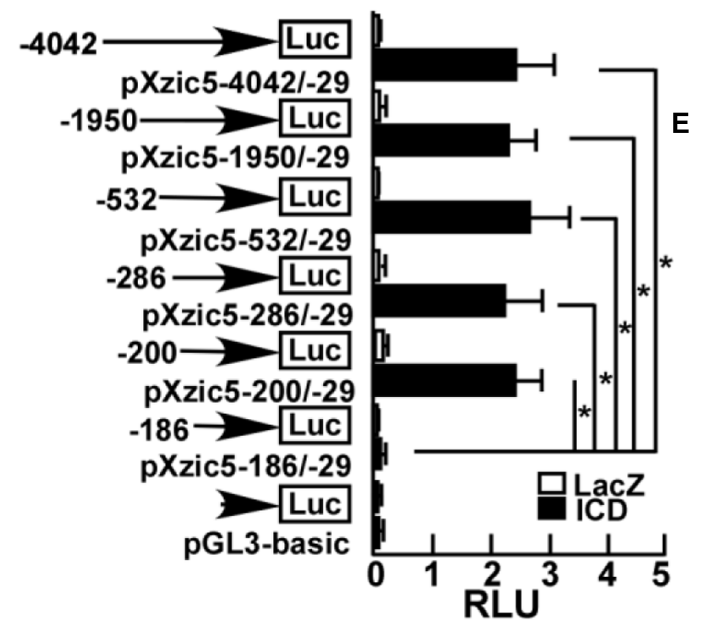

C $-200 \quad-186$

ACAGCCAGCCAATCA LUC

$15 \mathrm{bp}$ critical binding site

pXzic5-200

TTCTAATTAAGGATT LUC

pXzic5-200M

D

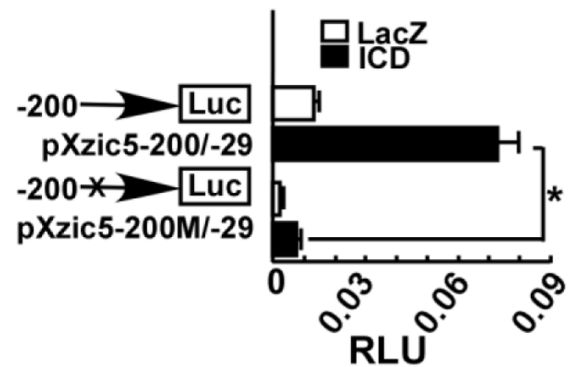

E

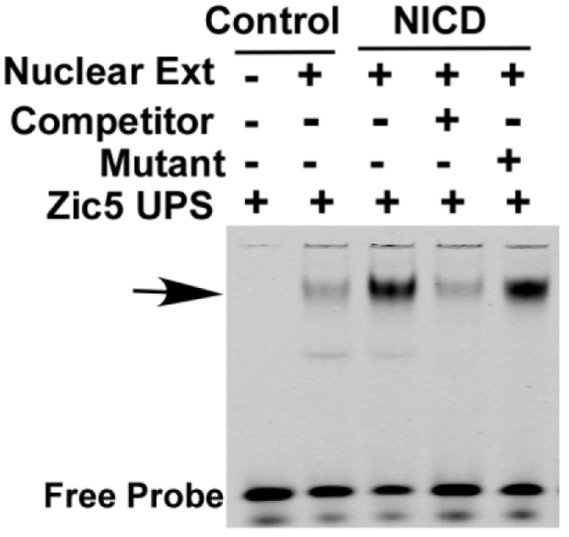

FIGURE 5 | Identification of a novel NRE in Xenopus Zic5. (A) A 4 kb region (-4042 to -29) upstream of Zic5 contains a Zic5 promoter. Mutations of two putative canonical CSL binding sites within this $4 \mathrm{~kb}$ region did not affect notch's activation of promoter activity. X's represent the mutated site. (B) Deletion assay of Zic5 upstream regulatory sequence identified a $15 \mathrm{bp}$ NRE locating between -200 and -186 bp in response to NICD activation. $P$-values relative to -186/-29 fragment are -200/-29 ( $P=0.004) ;-286 /-29(P=0.015) ;-533 /-29(P=0.013) ;-1950 /-29$ ( $P=0.004) ;-4042 /-29$ ( $P=0.014)$. (C) Diagram of the constructs containing 15 bp CSL sequence and mutations in the promoter constructs. pXZic5-200 represents the wild-type and pXZic5-200M represents the 15 bp CBS mutant plasmid. (D) Mutation of the 15 bp CBS (pXZic5-200M) abolished the activation triggered by NICD in the reporter assay; $P=0.0017$. (E) EMSA assay; NICD expression increased protein binding to the $15 \mathrm{bp}$ NRE (see section "Materials and Methods"). The number represents Mean \pm SEM, $N=3,{ }^{*} P<0.05$ with the post hoc Newman-Keuls test. RLU, relative luminant unit; Nuclear Ext, nuclear extraction; Zic5 UPS, fluorescent-labeling zic5 upstream Notch response element.

$(2.36 \pm 0.45$ RLU), -532 bp $(2.73 \pm 0.063$ RLU $),-286$ bp $(2.30 \pm 0.62 \mathrm{RLU})$, and $-200 \mathrm{bp}(2.48 \pm 0.42 \mathrm{RLU})$ upstream of Zic5 ORF with similar activation. A further deletion of $15 \mathrm{bp}$ lead to a sharply reduced luciferase activity in pXzic5-186/-29 $(0.187 \pm 0.099 \mathrm{RLU})(P<0.05)$ (Figure 5B). Therefore, the $15 \mathrm{bp}$ sequence ( 5 -ACAGCCAGCCAATCA) located between -200 and -186 bp upstream of Zic5 was identified to contain a functional NRE. To confirm the results, we generated a new plasmid pXzic5-200M containing mutations in the NRE (Figure 5C). The Zic5 upstream $200 \mathrm{bp}$ reporter plasmid containing the $15 \mathrm{bp}$ NRE was strongly activated by NICD $(0.073 \pm 0.0069$ RLU), and the mutations in the $15 \mathrm{bp}$ sequence to disrupt the NRE $(0.007 \pm 0.0009$ RLU) abolished the activation of Zic5 by NICD (Figure 5D).

Electrophoretic mobility shift assay (EMSA) was performed to further examine whether Notch signaling activation promotes the binding of the transcriptional factors to the 15 bp NRE. Nuclear proteins with or without NICD-transfected were extracted from SHSY5Y cells. NICD-transfection significantly increased the amount of the protein-NRE DNA binding complex (Figure 5E). The competitor probe containing the same non-fluorescently labeled $15 \mathrm{bp}$ sequence reversed the fluorescent binding signaling to background level, and a mutant probe had little effect to compete with the binding (Figure 5E). These results unequivocally demonstrate that Notch activates Zic5 expression via the newly identified 15 bp NRE.

\section{DISCUSSION}

Ketamine is a dissociative anesthetic and the most popular club drug abused by youths for recreational purposes (Lee et al., 2015). Lately ketamine has attracted extensive attention for its quick and significant alleviation of depression (DiazGranados et al., 2010; 
Li et al., 2011). Ketamine usage grows steadily. Young people, including those at childbearing age, are a major addict-prone population. In human, NC induction happens within the first month of pregnancy. At this early point in the pregnancy, most women are not aware that they are pregnant until the next regular menstrual cycle. While ketamine exposure has been shown to affect cell survival (Brambrink et al., 2012; Bai et al., 2013), germ layer specification (Akeju et al., 2014), neurogenesis (Cuevas et al., 2013; Kanungo et al., 2013; Dong et al., 2014), cardiac morphogenesis (Guo et al., 2016), and craniofacial and trunk genesis (Felix et al., 2017), the effect of ketamine on early embryonic development is poorly understood.

In this study, we discovered that early embryonic ketamine exposure specifically blocks NC induction via targeting Zic5. This effect on the NC is not due to the disruption of the mesoderm. Previous studies suggested the vital roles of Zic5 in NC genesis in mouse and Xenopus (Nakata et al., 2000; Inoue et al., 2004). Zic5 also works downstream of Wnt pathways and regulates tectum cell proliferation in zebrafish (Nyholm et al., 2007). However, the upstream signals regulating Zic5 expression in NC induction were not yet known. Our work revealed that the expression of Zic5 is controlled by Notch signaling during NC induction. Ketamine inhibited Notch targeted gene expression in Xenopus embryos. Xenopus embryos exposed to ketamine also exhibited shortened somite-segmentation, a typical Notch signaling deficiency phenotype. The Notch signaling pathway has long been known to participate in NC induction (Glavic et al., 2004; Kuriyama et al., 2006). In the neural-epidermal boundary, Notch balances BMP via activation of Hairy2 expression (Glavic et al., 2004). However other reports showed that Hairy2 is not regulated by Notch, but activates Notch via Stat3 (Nichane et al., 2008a,b). In this study, we demonstrated that Zic5 is a Notch targeted border gene involved in Xenopus NC induction. We also identified a 15 bp cis-acting element in the $5^{\prime}$ regulatory region of Xenopus Zic5 gene that binds to NICD to mediate Notch's transcriptional activation of Zic5 gene expression. Our

\section{REFERENCES}

Akeju, O., Davis-Dusenbery, B. N., Cassel, S. H., Ichida, J. K., and Eggan, K. (2014). Ketamine exposure in early development impairs specification of the primary germ cell layers. Neurotoxicol. Teratol. 43, 59-68. doi: 10.1016/j.ntt.2014. 04.001

Artavanis-Tsakonas, S., Matsuno, K., and Fortini, M. E. (1995). Notch signaling. Science 268, 225-232.

Artavanis-Tsakonas, S., Rand, M. D., and Lake, R. J. (1999). Notch signaling: cell fate control and signal integration in development. Science 284, 770-776.

Bai, X., Yan, Y., Canfield, S., Muravyeva, M. Y., Kikuchi, C., Zaja, I., et al. (2013). Ketamine enhances human neural stem cell proliferation and induces neuronal apoptosis via reactive oxygen species-mediated mitochondrial pathway. Anesth. Analg. 116, 869-880. doi: 10.1213/ANE.0b013e3182860fc9

Bolande, R. P. (1997). Neurocristopathy: its growth and development in 20 years. Pediatr. Pathol. Lab. Med. 17, 1-25.

Bozkulak, E. C., and Weinmaster, G. (2009). Selective use of ADAM10 and ADAM17 in activation of Notch1 signaling. Mol. Cell. Biol. 29, 5679-5695. doi: 10.1128/MCB.00406-09

Brambrink, A. M., Evers, A. S., Avidan, M. S., Farber, N. B., Smith, D. J., Martin, L. D., et al. (2012). Ketamine-induced neuroapoptosis in the fetal and neonatal rhesus macaque brain. Anesthesiology 116, 372-384. doi: 10.1097/ ALN.0b013e318242b2cd study further showed that ketamine enhanced ubiquitination of Notch proteins, and reduced Notch-1 protein level. These data suggest that enhanced degradation of Notch protein by ketamine may partly account for the phenotypes we observed in Xenopus, consistent with the similar phenotypes in Zebrafish (Felix et al., 2017). These results suggest a conserved mechanism of ketamine among different spices.

In summary, we discovered that Zic5 works as a downstream target gene of Notch signaling in Xenopus NC induction. Our study provides a novel teratogenic mechanism for ketamine whereby it disrupts NC induction by targeting a Notch-Zic5 signaling pathway.

\section{AUTHOR CONTRIBUTIONS}

YS, JL, and WS conceived and designed the experiments. YS, JL, CC, YXi, YL, and YXu performed the experiments. YS, JL, YXi, YXu, TL, and WS analyzed and contributed reagents/materials/analysis tools. YS, JL, and WS wrote the paper. All authors reviewed the manuscript.

\section{ACKNOWLEDGMENTS}

This work was supported by the National Natural Science Foundation of China (NSFC) (81102519 and 81771596 to YS), (81200878 to JL), and (81200440 to YXi) the China Postdoctoral Science Foundation funded project (2012M511914 to YS), the Chongqing Science and Technology Committee (CSTC2012jjA10095 and CSTC2015jcyjBX0095 to YS) and Chongqing Municipal Bureau of Health and Family Planning Project (2015MSXM036 to YS), and Canadian Institutes of Health Research (CIHR) Grant TAD-117948 (WS). WS is the holder of the Tier 1 Canada Research Chair in Alzheimer's Disease.

Brou, C., Logeat, F., Gupta, N., Bessia, C., LeBail, O., Doedens, J. R., et al. (2000). A novel proteolytic cleavage involved in Notch signaling: the role of the disintegrin-metalloprotease TACE. Mol. Cell. 5, 207-216.

Cuevas, E., Trickler, W. J., Guo, X., Ali, S. F., Paule, M. G., and Kanungo, J. (2013). Acetyl L-carnitine protects motor neurons and Rohon-Beard sensory neurons against ketamine-induced neurotoxicity in zebrafish embryos. Neurotoxicol. Teratol. 39, 69-76. doi: 10.1016/j.ntt.2013.07.005

Dale, J. K., Maroto, M., Dequeant, M. L., Malapert, P., McGrew, M., and Pourquie, O. (2003). Periodic notch inhibition by lunatic fringe underlies the chick segmentation clock. Nature 421, 275-278.

de Croze, N., Maczkowiak, F., and Monsoro-Burq, A. H. (2011). Reiterative AP2a activity controls sequential steps in the neural crest gene regulatory network. Proc. Natl. Acad. Sci. U.S.A. 108, 155-160. doi: 10.1073/pnas.1010740107

De Strooper, B., Annaert, W., Cupers, P., Saftig, P., Craessaerts, K., Mumm, J. S., et al. (1999). A presenilin-1-dependent gamma-secretase-like protease mediates release of Notch intracellular domain. Nature 398, 518-522.

DiazGranados, N., Ibrahim, L. A., Brutsche, N. E., Ameli, R., Henter, I. D., Luckenbaugh, D. A., et al. (2010). Rapid resolution of suicidal ideation after a single infusion of an N-methyl-D-aspartate antagonist in patients with treatment-resistant major depressive disorder. J. Clin. Psychiatry 71, 1605-1611. doi: 10.4088/JCP.09m05327blu

Dong, C., and Anand, K. J. (2013). Developmental neurotoxicity of ketamine in pediatric clinical use. Toxicol. Lett. 220, 53-60. doi: 10.1016/j.toxlet.2013.03.030 
Dong, C., Rovnaghi, C. R., and Anand, K. J. (2014). Ketamine affects the neurogenesis of rat fetal neural stem progenitor cells via the PI3K/Akt-p27 signaling pathway. Birth Defects Res. B Dev. Reprod. Toxicol. 101, 355-363. doi: 10.1002/bdrb.21119

Dyczynska, E., Sun, D., Yi, H., Sehara-Fujisawa, A., Blobel, C. P., and Zolkiewska, A. (2007). Proteolytic processing of delta-like 1 by ADAM proteases. J. Biol. Chem. 282, 436-444.

Endo, Y., Osumi, N., and Wakamatsu, Y. (2002). Bimodal functions of Notchmediated signaling are involved in neural crest formation during avian ectoderm development. Development 129, 863-873.

Felix, L. M., Antunes, L. M., and Coimbra, A. M. (2014). Ketamine NMDA receptor-independent toxicity during zebrafish (Danio rerio) embryonic development. Neurotoxicol. Teratol. 41, 27-34. doi: 10.1016/j.ntt.2013.11.005

Felix, L. M., Serafim, C., Martins, M. J., Valentim, A. M., Antunes, L. M., Matos, M., et al. (2017). Morphological and behavioral responses of zebrafish after 24h of ketamine embryonic exposure. Toxicol. Appl. Pharmacol. 321, 27-36. doi: 10.1016/j.taap.2017.02.013

Fryer, C. J., Lamar, E., Turbachova, I., Kintner, C., and Jones, K. A. (2002). Mastermind mediates chromatin-specific transcription and turnover of the Notch enhancer complex. Genes Dev. 16, 1397-1411.

Glavic, A., Silva, F., Aybar, M. J., Bastidas, F., and Mayor, R. (2004). Interplay between Notch signaling and the homeoprotein Xirol is required for neural crest induction in Xenopus embryos. Development 131, 347-359.

Guemar, L., de Santa Barbara, P., Vignal, E., Maurel, B., Fort, P., and Faure, S. (2007). The small GTPase RhoV is an essential regulator of neural crest induction in Xenopus. Dev. Biol. 310, 113-128.

Guo, R., Liu, G., Du, M., Shi, Y., Jiang, P., Liu, X., et al. (2016). Early ketamine exposure results in cardiac enlargement and heart dysfunction in Xenopus embryos. BMC Anesthesiol. 16:23. doi: 10.1186/s12871-016-0188-z

Hernandez-Lagunas, L., Powell, D. R., Law, J., Grant, K. A., and Artinger, K. B. (2011). prdmla and olig4 act downstream of Notch signaling to regulate cell fate at the neural plate border. Dev. Biol. 356, 496-505. doi: 10.1016/j.ydbio. 2011.06.005

Inoue, T., Hatayama, M., Tohmonda, T., Itohara, S., Aruga, J., and Mikoshiba, K. (2004). Mouse Zic5 deficiency results in neural tube defects and hypoplasia of cephalic neural crest derivatives. Dev. Biol. 270, 146-162.

Ionescu, D. F., Luckenbaugh, D. A., Niciu, M. J., Richards, E. M., and Zarate, C. A. Jr. (2015). A single infusion of ketamine improves depression scores in patients with anxious bipolar depression. Bipolar Disord. 17, 438-443. doi: 10.1111/bdi.12277

Jen, W. C., Wettstein, D., Turner, D., Chitnis, A., and Kintner, C. (1997). The Notch ligand, X-Delta-2, mediates segmentation of the paraxial mesoderm in Xenopus embryos. Development 124, 1169-1178.

Kanungo, J., Cuevas, E., Ali, S. F., and Paule, M. G. (2013). Ketamine induces motor neuron toxicity and alters neurogenic and proneural gene expression in zebrafish. J. Appl. Toxicol. 33, 410-417. doi: 10.1002/jat.1751

Kinoshita, T., Haruta, Y., Sakamoto, C., and Imaoka, S. (2011). Antagonistic role of XESR1 and XESR5 in mesoderm formation in Xenopus laevis. Int. J. Dev. Biol. 55, 25-31. doi: 10.1387/ijdb.092990tk

Kirby, T. (2015). Ketamine for depression: the highs and lows. Lancet Psychiatry 2, 783-784.

Klymkowsky, M. W., Rossi, C. C., and Artinger, K. B. (2010). Mechanisms driving neural crest induction and migration in the zebrafish and Xenopus laevis. Cell Adh. Migr. 4, 595-608.

Kuriyama, S., Lupo, G., Ohta, K., Ohnuma, S., Harris, W. A., and Tanaka, H. (2006). Tsukushi controls ectodermal patterning and neural crest specification in Xenopus by direct regulation of BMP4 and X-delta-1 activity. Development $133,75-88$.

Lantz-McPeak, S., Guo, X., Cuevas, E., Dumas, M., Newport, G. D., Ali, S. F., et al. (2015). Developmental toxicity assay using high content screening of zebrafish embryos. J. Appl. Toxicol. 35, 261-272. doi: 10.1002/jat.3029

Lee, E. E., Della Selva, M. P., Liu, A., and Himelhoch, S. (2015). Ketamine as a novel treatment for major depressive disorder and bipolar depression: a systematic review and quantitative meta-analysis. Gen. Hosp. Psychiatry 37, 178-184. doi: 10.1016/j.genhosppsych.2015.01.003

Li, H. Y., Bourdelas, A., Carron, C., Gomez, C., Boucaut, J. C., and Shi, D. L. (2006). FGF8, Wnt8 and Myf5 are target genes of Tbx6 during anteroposterior specification in Xenopus embryo. Dev. Biol. 290, 470-481.
Li, J. H., Vicknasingam, B., Cheung, Y. W., Zhou, W., Nurhidayat, A. W., Jarlais, D. C., et al. (2011). To use or not to use: an update on licit and illicit ketamine use. Subst. Abuse Rehabil. 2, 11-20. doi: 10.2147/SAR. S15458

Linker, C., De Almeida, I., Papanayotou, C., Stower, M., Sabado, V., Ghorani, E., et al. (2009). Cell communication with the neural plate is required for induction of neural markers by BMP inhibition: evidence for homeogenetic induction and implications for Xenopus animal cap and chick explant assays. Dev. Biol. 327, 478-486. doi: 10.1016/j.ydbio.2008.12.034

Luo, T., Lee, Y. H., Saint-Jeannet, J. P., and Sargent, T. D. (2003). Induction of neural crest in Xenopus by transcription factor AP2alpha. Proc. Natl. Acad. Sci. U.S.A. 100, 532-537.

Luo, T., Matsuo-Takasaki, M., and Sargent, T. D. (2001). Distinct roles for Distalless genes Dlx 3 and Dlx5 in regulating ectodermal development in Xenopus. Mol. Reprod. Dev. 60, 331-337.

Luo, T., Matsuo-Takasaki, M., Thomas, M. L., Weeks, D. L., and Sargent, T. D. (2002). Transcription factor AP-2 is an essential and direct regulator of epidermal development in Xenopus. Dev. Biol. 245, 136-144.

McLarren, K. W., Litsiou, A., and Streit, A. (2003). DLX5 positions the neural crest and preplacode region at the border of the neural plate. Dev. Biol. 259, 34-47.

Mead, T. J., and Yutzey, K. E. (2012). Notch pathway regulation of neural crest cell development in vivo. Dev. Dyn. 241, 376-389. doi: 10.1002/dvdy. 23717

Milet, C., and Monsoro-Burq, A. H. (2012). Neural crest induction at the neural plate border in vertebrates. Dev. Biol. 366, 22-33. doi: 10.1016/j.ydbio.2012. 01.013

Mizuseki, K., Kishi, M., Matsui, M., Nakanishi, S., and Sasai, Y. (1998). Xenopus Zic-related-1 and Sox-2, two factors induced by chordin, have distinct activities in the initiation of neural induction. Development 125, 579-587.

Monsoro-Burq, A. H. (2015). PAX transcription factors in neural crest development. Semin. Cell Dev. Biol. 44, 87-96. doi: 10.1016/j.semcdb.2015. 09.015

Monsoro-Burq, A. H., Fletcher, R. B., and Harland, R. M. (2003). Neural crest induction by paraxial mesoderm in Xenopus embryos requires FGF signals. Development 130, 3111-3124.

Monsoro-Burq, A. H., Wang, E., and Harland, R. (2005). Msx1 and Pax3 cooperate to mediate FGF8 and WNT signals during Xenopus neural crest induction. Dev. Cell 8, 167-178.

Montagner, M., Martello, G., and Piccolo, S. (2016). Monitoring Smad activity in vivo using the Xenopus model system. Methods Mol. Biol. 1344, 245-259. doi: 10.1007/978-1-4939-2966-5_15

Mumm, J. S., Schroeter, E. H., Saxena, M. T., Griesemer, A., Tian, X., Pan, D. J., et al. (2000). A ligand-induced extracellular cleavage regulates gamma-secretase-like proteolytic activation of Notch1. Mol. Cell. 5, 197-206.

Nakata, K., Koyabu, Y., Aruga, J., and Mikoshiba, K. (2000). A novel member of the Xenopus Zic family, Zic5, mediates neural crest development. Mech. Dev. 99, 83-91.

Nichane, M., de Croze, N., Ren, X., Souopgui, J., Monsoro-Burq, A. H., and Bellefroid, E. J. (2008a). Hairy2-Id3 interactions play an essential role in Xenopus neural crest progenitor specification. Dev. Biol. 322, 355-367. doi: 10.1016/j.ydbio.2008.08.003

Nichane, M., Ren, X., Souopgui, J., and Bellefroid, E. J. (2008b). Hairy2 functions through both DNA-binding and non DNA-binding mechanisms at the neural plate border in Xenopus. Dev. Biol. 322, 368-380. doi: 10.1016/j.ydbio.2008. 07.026

Nyholm, M. K., Wu, S. F., Dorsky, R. I., and Grinblat, Y. (2007). The zebrafish zic2a-zic5 gene pair acts downstream of canonical Wnt signaling to control cell proliferation in the developing tectum. Development 134, 735-746.

Okamura, Y., and Saga, Y. (2008). Notch signaling is required for the maintenance of enteric neural crest progenitors. Development 135, 3555-3565. doi: 10.1242/ dev.022319

Oschwald, R., Richter, K., and Grunz, H. (1991). Localization of a nervous systemspecific class II beta-tubulin gene in Xenopus laevis embryos by whole-mount in situ hybridization. Int. J. Dev. Biol. 35, 399-405.

Reardon, S. (2015). Rave drug tested against depression. Nature 517, 130-131.

Revinski, D. R., Paganelli, A. R., Carrasco, A. E., and Lopez, S. L. (2010). DeltaNotch signaling is involved in the segregation of the three germ layers in Xenopus laevis. Dev. Biol. 339, 477-492. doi: 10.1016/j.ydbio.2010.01.010 
Robinson, B. L., Dumas, M., Paule, M. G., Ali, S. F., and Kanungo, J. (2015). Opposing effects of ketamine and acetyl l-carnitine on the serotonergic system of zebrafish. Neurosci. Lett. 607, 17-22. doi: 10.1016/j.neulet.2015.09.006

Sasai, Y., Lu, B., Steinbeisser, H., Geissert, D., Gont, L. K., and De Robertis, B. N. (1994). Xenopus chordin: a novel dorsalizing factor activated by organizerspecific homeobox genes. Cell 79, 779-790.

Schroeter, E. H., Kisslinger, J. A., and Kopan, R. (1998). Notch-1 signalling requires ligand-induced proteolytic release of intracellular domain. Nature 393, 382-386.

Shi, Y., Li, J., Chen, C., Gong, M., Chen, Y., Liu, Y., et al. (2014). 5-mehtyltetrahydrofolate rescues alcohol-induced neural crest cell migration abnormalities. Mol. Brain 7:67. doi: 10.1186/s13041-014-0067-9

Shi, Y., Zhao, S., Li, J., and Mao, B. (2009). Islet-1 is required for ventral neuron survival in Xenopus. Biochem. Biophys. Res. Commun. 388, 506-510. doi: 10.1016/j.bbrc.2009.08.017

Shyamala, K., Yanduri, S., Girish, H. C., and Murgod, S. (2015). Neural crest: the fourth germ layer. J. Oral Maxillofac. Pathol. 19, 221-229. doi: 10.4103/0973029X.164536

Smith, J. C., Price, B. M., Green, J. B., Weigel, D., and Herrmann, B. G. (1991). Expression of a Xenopus homolog of Brachyury (T) is an immediate-early response to mesoderm induction. Cell 67, 79-87.

Song, W., Nadeau, P., Yuan, M., Yang, X., Shen, J., and Yankner, B. A. (1999). Proteolytic release and nuclear translocation of Notch-1 are induced by presenilin-1 and impaired by pathogenic presenilin-1 mutations. Proc. Natl. Acad. Sci. U.S.A. 96, 6959-6963.

Steventon, B., Araya, C., Linker, C., Kuriyama, S., and Mayor, R. (2009). Differential requirements of BMP and Wnt signalling during gastrulation and neurulation define two steps in neural crest induction. Development 136, 771-779. doi: 10.1242/dev.029017

Steventon, B., Carmona-Fontaine, C., and Mayor, R. (2005). Genetic network during neural crest induction: from cell specification to cell survival. Semin. Cell Dev. Biol. 16, 647-654.

Struhl, G., and Adachi, A. (1998). Nuclear access and action of notch in vivo. Cell 93, 649-660.

Su, M. W., Suzuki, H. R., Solursh, M., and Ramirez, F. (1991). Progressively restricted expression of a new homeobox-containing gene during Xenopus laevis embryogenesis. Development 111, 1179-1187.
Takahashi, Y., Sipp, D., and Enomoto, H. (2013). Tissue interactions in neural crest cell development and disease. Science 341, 860-863. doi: 10.1126/science. 1230717

Theveneau, E., and Mayor, R. (2012). Neural crest delamination and migration: from epithelium-to-mesenchyme transition to collective cell migration. Dev. Biol. 366, 34-54. doi: 10.1016/j.ydbio.2011.12.041

Tribulo, C., Aybar, M. J., Nguyen, V. H., Mullins, M. C., and Mayor, R. (2003). Regulation of Msx genes by a Bmp gradient is essential for neural crest specification. Development 130, 6441-6452.

Trost, A., Schroedl, F., Lange, S., Rivera, F. J., Tempfer, H., Korntner, S., et al. (2013). Neural crest origin of retinal and choroidal pericytes. Invest. Ophthalmol. Vis. Sci. 54, 7910-7921. doi: 10.1167/iovs.13-12946

Vega-Lopez, G. A., Bonano, M., Tribulo, C., Fernandez, J. P., Aguero, T. H., and Aybar, M. J. (2015). Functional analysis of Hairy genes in Xenopus neural crest initial specification and cell migration. Dev. Dyn. 244, 988-1013. doi: $10.1002 /$ dvdy. 24295

Wang, R., Zhang, M., Zhou, W., Ly, P. T., Cai, F., and Song, W. (2011). NF-kappaB signaling inhibits ubiquitin carboxyl-terminal hydrolase L1 gene expression. J. Neurochem. 116, 1160-1170. doi: 10.1111/j.1471-4159.2011.07172.x

Zhang, Z., Nadeau, P., Song, W., Donoviel, D., Yuan, M., Bernstein, A., et al. (2000). Presenilins are required for gamma-secretase cleavage of beta-APP and transmembrane cleavage of Notch-1. Nat. Cell Biol. 2, 463-465.

Zhang, Z., Shi, Y., Zhao, S., Li, J., Li, C., and Mao, B. (2014). Xenopus Nkx6.3 is a neural plate border specifier required for neural crest development. PLOS ONE 9:e115165. doi: 10.1371/journal.pone.0115165

Conflict of Interest Statement: The authors declare that the research was conducted in the absence of any commercial or financial relationships that could be construed as a potential conflict of interest.

Copyright (c) 2018 Shi, Li, Chen, Xia, Li, Zhang, Xu, Li, Zhou and Song. This is an open-access article distributed under the terms of the Creative Commons Attribution License (CC BY). The use, distribution or reproduction in other forums is permitted, provided the original author(s) and the copyright owner are credited and that the original publication in this journal is cited, in accordance with accepted academic practice. No use, distribution or reproduction is permitted which does not comply with these terms. 